\title{
Sustained Participation in Virtual Communities from a Self-Determination Perspective
}

\author{
Zhe Zhang \\ School of Management, Fudan University, Shanghai 200433, China; zhezhang@fudan.edu.cn; \\ Tel.: +86-21-250-111-89 \\ Received: 5 September 2019; Accepted: 16 November 2019; Published: 20 November 2019
}

\begin{abstract}
Customers' participation and contribution are vital to the sustainability of virtual communities (VCs) platform while people have many options to freely surf on the Internet. Sustained participation, instead of initial participation, is more meaningful to virtual communities' sustained development. From the perspective of self-determination theory, this paper explores the effect of community artifacts on sustained participations through users' satisfaction of psychological need and virtual community identification. With empirical studies in two types of virtual community platforms (interest-based and relational-based), our results reveal several important findings. Firstly, this study finds that virtual co-presence and deep profiling can increase users' satisfaction of inner psychological needs. But the use of persistent labeling does not affect the user's satisfaction of psychological needs. In addition, self-presentation is positively related to relational-based community, and rather has no impact on interest-based community. Secondly, this study finds that there exists a positive relationship between users' satisfied psychological needs and virtual community identification. Finally, virtual community identification significantly impacts sustained participation. This paper offers a new perspective on the psychological mechanism of sustained participation and yields important implications for the managerial practice.
\end{abstract}

Keywords: sustained participation; sustainability; self-determination theory; virtual community identification; basic psychological needs; community artifacts

\section{Introduction}

The issue of user participation in virtual community platforms is receiving increasing attention from business practitioners and academics [1-7]. The majority of virtual community contents including knowledge, social support, friendship, and entertainment are dependent on voluntary contributions by community members. Therefore, active participation of virtual community members is considered to be the core of sustainability of the community and has been identified as an important measure for online community performance [8]. From the perspective of organizers, the participation rate directly determines business value and potential profitability. A key to successfully carry out online customer community in today's era is in motivating and maintaining virtual community members to continuously become actively involved in the long-term [9-11].

Some of the management scholars have researched VC participation behavior through a motivation or identification theory perspective $[9,12-14]$ However, these studies do not distinguish the pattern of participation in virtual communities. The sustained participation behavior from the perspective of the psychological mechanism has even more theoretical and practical value for researchers and practitioners [10,15].

This study argues that the self-determination theory (SDT) provides a theoretical framework to comprehend the psychological mechanisms related to the sustained participation behaviors of virtual community members. SDT reveals the process of how an external environment promotes 
internalization mechanisms of intrinsic and extrinsic motivation [16]. Because in the virtual community context, satisfying users' intrinsic and extrinsic motivation is a key mechanism for motivating users toward sustained participation $[17,18]$.

The sustained participation of online communities is a form of source usage [19]. This study adopts source usage from [17] about virtual community artifacts including virtual copresence, persistent labeling, self-presentation, and deep profiling. This study explores the psychological mechanisms of virtual community members and their sustained participation behaviors behind the users' perceived effectiveness of community artifacts in virtual communities from the perspective of the self-determination theory. Beyond identification with virtual communities, this study aims to put forward the antecedents driving virtual community identification through fulfillment of basic psychological needs. These issues contribute to contemporary organizational sustainability research for information technologies [19-21].

In the next section, based on theoretical background, this study proposes a theoretical framework and research hypotheses. This framework in two virtual communities was tested because I expected differences between an interest-based and a relational-based service community. Finally, a general discussion of our findings is concluded and managerial implications and future research directions are derived.

\section{Theoretical Background}

\subsection{Sustained Participation}

Participation behavior in community behavior is essentially described in terms of the common following factors: members' voluntary involvement, the requirements of members' creative efforts, and the critical role of participation in the sustained development of the community $[8,22]$.

Furthermore, the classification of virtual community participation lays more emphasis on a static base instead of a dynamic one considering the members' psychological changes from the initial participation to sustained participation $[19,23,24]$. This establishes the distinction between initial participation and sustained participation. Some scholars have noted that there are different motivating factors for sustained participation and initial participation [25,26]. As Shah [26] finds, drivers for short-term and long-term participants in a software community are not the same. The former mainly seeks to meet the needs of searching software, while the latter is driven by hobby for programming and the like, and for interacting with other members of the community. In the research about Public Document Repositories, Peddibhotla and Subramani [25] view members' contribution to Public Document Repositories as one type of participation behavior. They also point out that this kind of behavior is determined by two aspects: contribution quantity and quality, which are also different in terms of their inner motivations.

Therefore, one characteristic of sustained participation is continuous voluntary contribution [27]. Why do members choose to participate in such a way? Ma and Agarwal [17] study the influence of contextual characteristics on participant's knowledge sharing from the perspective of identity verification. Furthermore, Toubia and Stephen [14] use Twitter as an example to study why people are willing to contribute content and knowledge through social media based on intrinsic utility and image-related utility. Similarly, social constructionists view that people acquire information and knowledge through an interactive process with other people, resulting in the formation of a community membership [28,29]. Such a highly contextualized learning process and identity can directly affect the user community's participation behavior [8,9]. Further, Porter et al. [30] suggest that managers can adopt a three-stage process to successfully nurture and maintain consumers' sustained participation in virtual communities, which is first to understand consumer needs and motivations, second to promote participation, and third to encourage cooperation. In addition, Lin and $\mathrm{Lu}$ [15] propose a rational model that integrates motivation theory with network externalities to interpret users' continuously join 
in social network sites. Fang and Zhang [10] analyze different users' continued participation behavior in social Q\&A communities from a motivation perspective.

\subsection{Self-Determination Theory}

We adopt self-determination theory (SDT) as the theoretical perspective. In recent years, the self-determination theory has especially received widespread attention (e.g., [12,19,31]). Deci and Ryan $[32,33]$ develop the self-determination theory to understand what sustains individual behavior. The self-determination theory reveals the impact of external influences on individual motivation from an organic and dialectical perspective and describes the process of how an external environment promotes internalization mechanisms of intrinsic and extrinsic motivation [16].

The basic psychological needs theory branches from the self-determination theory [34]. Researchers identify three basic psychological needs: the need for autonomy, the need for competence, and the need for relatedness. The self-determination theory identifies human motivation by two categories-intrinsic and extrinsic-which are not antagonistic, but exist in a continuum. Intrinsic motivation does not weaken with the presence of extrinsic motivation [13]. Intrinsic motivation refers to doing an act in order to gain pleasure and satisfaction authentically; extrinsic motivation refers to the performance of an activity to attain some separable outcome. According to the self-determination theory, intrinsic motivation and extrinsic motivation internalization is a natural process. Whether or not this process can be successfully completed depends on whether or not the three basic psychological needs in this process can be met.

\subsection{Virtual Community Identification}

Virtual community identification is a specific type of organizational identification. The process of organizational identification occurs as individuals' self-concept come to share attributes in common with their organization $[34,35]$. Such identification and self-categorization processes also exist within the virtual context [36]. Virtual community identification refers to the users' identifying themselves with the virtual community [8]. Individual social identity construction comes from his/her cognitive recognition of membership in one group, as well as his/her affective connection and personal evaluation [37].

Ellemers et al. [38] proposed three components of social identification: cognitive, affective and evaluative. Cognitive component refers to one's cognition of a group's membership after self-categorization process. Cognitive component of social identification demonstrates a process to identify and strengthen their similarities to other members of the organization, as well as differences from non- members of the group [39]. The affective component is a personal emotional connection to the belonged group. Even such a group is virtual [8]. The affective component determines whether the members love such groups. The evaluative component is a personal positive or negative evaluation towards his/her membership of one group they belong to, which actually yields the formation of self-esteem at organizational level [38].

\section{Theoretical Framework and Hypotheses}

Building on the self-determination theory and virtual community identification, our theoretical framework is shown in Figure 1. According to [17], there are four technical features of virtual communities including virtual copresence, persistent labeling, self-presentation, and deep profiling. To sustain the behavior of using an online community and share knowledge, the behavior has to be self-determined $[6,12,19,40]$. The community artifacts amplify the satisfaction of basic psychological needs, which strengthens virtual community identification, which, in turn, relates to sustained participation. Our theoretical framework figures out the underlying mechanism of the virtual community identification process through the perspective of members' basic psychological needs fulfillment. 


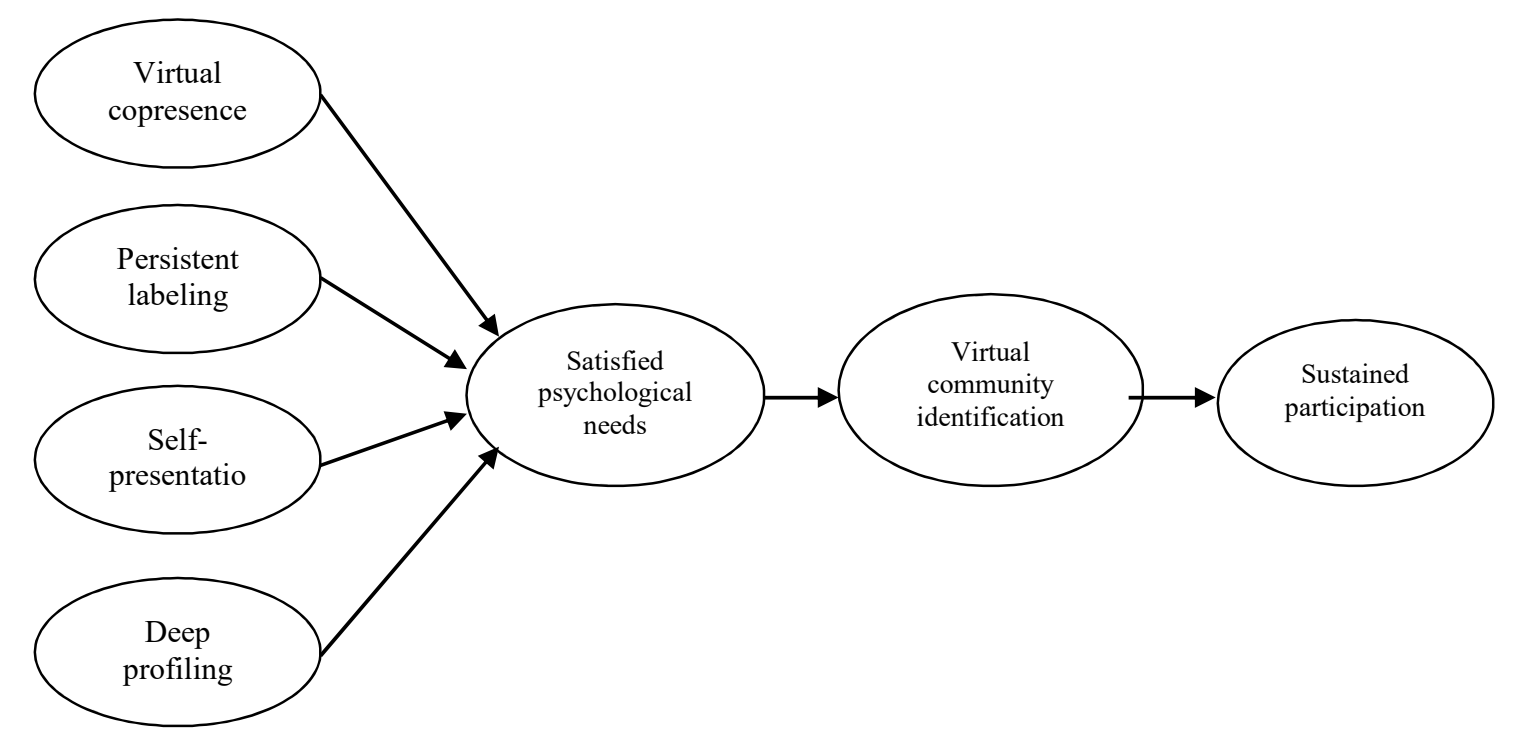

Figure 1. Theoretical framework.

\subsection{Community Artifacts and Satisfied Psychological Needs}

Virtual copresence refers to individuals subjectively feeling being together with the others in a virtual environment. Many factors affect this subjective feeling such as interactivity (using instant messaging tools such as chat rooms or instant messaging), media vividness (such as how many users are available online, what they are doing). When the users are able to feel this virtual copresence, knowing each other also with a virtual community, their communication with each other can get immediate feedback, and they feel care and attention by the other party. Then, the users' psychological needs will be satisfied. Therefore, based on the discussion summarized above, the study proposes the following hypothesis:

Hypothesis 1a (H1a). Community artifact supporting virtual copresence is positively related to satisfaction of psychological needs.

Persistent labeling refers to an individual consistently using the same user name (ID) or label (label) for a long time in a virtual environment. The lack of information about self and others will inhibit the interaction between anonymous members in a virtual environment. When a user uses a continuous label, he can be more easily identified by others. Information exchange is much simpler and easier to establish a stable relationship with others. When the user is always constantly changing labels, as it is more difficult to be identified, others may also be mistaken for a different user. Therefore it becomes more difficult to establish relationships with others, albeit the exchange of information. Therefore, this study proposes:

Hypothesis $\mathbf{1 b} \mathbf{( H 1 b ) . ~ C o m m u n i t y ~ a r t i f a c t ~ s u p p o r t i n g ~ p e r s i s t e n t ~ l a b e l i n g ~ i s ~ p o s i t i v e l y ~ r e l a t e d ~ t o ~ s a t i s f a c t i o n ~ o f ~}$ psychological needs.

Self-presentation is represented using a variety of ways such as a personal home page, personalized signature, screen name, avatar to represent themselves, which will make others understand themselves better. On the one hand, when the user can choose how to show their own, such as the ability to modify their own signature, the ability to choose their screen name and image, the ability to choose how to decorate their own personal home page, the user can experience the feeling of autonomy. To take control of their own image and behavior in a virtual environment means that they are their own masters. Such artifacts can promote intrinsic motivation or extrinsic motivation internalization for community members. What is more, virtual environments can support more users in the freedom to express their 
views, thereby strengthening their inner sense of autonomy. On the other hand, self-presentation can also provide others better understanding of their own way. Then, the users can more easily express their views and the characteristics of their hobbies, and it is easier to build a relationship with others who meet their social relatedness requirements. Therefore, the study proposes:

Hypothesis 1c (H1c). Community artifact supporting self-presentation is positively related to satisfaction of psychological needs.

Deep profiling refers to the virtual community providing more information about a user, such as ranking data (based on professional competence, credibility, contribution, or other criteria), interaction (with most members of the interaction, etc.), the user prior information, and effective search tools. These functions are able to allow users to be more convenient and more accurate in understanding others as well as themselves, which are more conducive to the establishment of mutual relations between the members. Therefore, the study proposes:

Hypothesis 1d (H1d). Community artifact supporting deep profiling is positively related to satisfaction of psychological needs.

\subsection{Satisfied Psychological Needs and Virtual Community Identification}

Humans spend a great deal of time, energy, and money in virtual contexts (such as video-gaming, blogging, chatting etc.). Recent empirical research indicates that virtual environments may be motivating to the degree that they allow individuals to experience ideal aspects of themselves [41,42]. On the other side, SDT suggests that three basic psychological needs are the essential constituents for identity development and well-being [32]. Therefore, we can speculate that social identities in VC are adopted in the service of these basic psychological needs [43].

In Marcia's paradigm [44], identity formation is operationally defined according to two dimensions, exploration, and commitment. Exploration refers to the degree to which individuals actively examine values, beliefs, and goals, and experiment with different social roles, plans, and ideologies. Commitment refers to the determined adherence to a set of convictions, goals and values. Luyckx et al. [45] find that the autonomous orientation was positively related to making commitments and feeling certain about commitment. Meanwhile, identity integration, a key element in identity exploration and development [46], was positively related to self-esteem and positive effects, which are the bases of affective and evaluative social identity in a virtual community [3]. Gagne and Deci [34] summarize that autonomous motivation is related to organizational commitment as indexed by identification and integration in a work context. Satisfaction of psychological needs will bring work engagement emotionally and increase general collective self-esteem [3,38]. Accordingly, VC participants will enhance their affective and evaluative social identity after satisfaction of intrinsic needs.

Competence need refers to an individual's faith to achieve a certain outcome after own behavior and to believe himself/herself capacity to take control of certain activities and the environment. In the virtual community, users' ability to act with a certain degree of confidence and control will help them to engage in the community deeper and longer which, in turn, will enhance their identification with the virtual group. Particularly, the competence of learning in the community is helpful to an individual's development of a social identity $[9,47]$.

Social identification with the virtual community originates from the individual member's innate need for belonging [9]. The sense of belonging yields understanding and meeting others' expectations within a group. At the same time, while the individual feels his relatedness, he will form a positive evaluation towards being in this community considering others' caring, understanding, and appreciation [48]. Identification reflects a conscious valuing of a behavioral goal or regulation, such that the action is accepted or owned as personally important. Therefore, satisfaction of psychological needs will integrate extrinsic motivation into an intrinsic one with an autonomous or self-determined 
form, resulting in the formation of social identity in a virtual community. This is summarized in the following hypothesis:

Hypothesis 2 (H2). Users' satisfied psychological needs are positively related to their virtual community identification.

\subsection{Virtual Community Identification and Sustained Participation}

Ellemers et al. [38] propose a form of social identity of three components: cognitive identity, affective identity and evaluative identity. Bergami and Bagozzi [49] using field observations find that three dimensions of social identity can contribute to employees' organizational citizenship behavior within the organizational context. Previous scholars also show that such an identity and self-categorization process also exists in a network environment [36].

Fang and Neufeld [50] propose that legitimate peripheral participation theory is composed of situated learning, identity construction, and sustained participation. Situated learning and identity construction interact with each other, which attribute to sustained participation [51]. Through situated learning, a member's ability is gradually recognized by both the community (through adjustment of status) and other community members (through identity activities). Furthermore enhanced identity promotes the members to join situated learning (meanwhile contributing to other's situated learning). The participants ultimately engage the sustained participation behavior through this process. Therefore, this process also explains that the identity construction can enhance sustained participation behavior. Tsai and Pai [52] testify that members' identification with the virtual community influences members' proactive participation behavior. Based on the above analysis, the study proposes Hypothesis 3 :

Hypothesis 3 (H3). Virtual community identification is positively related to sustained participation behavior for users.

\section{Methodology}

\subsection{Research Setting}

To test the proposed hypotheses, this study conducted a study in cooperation with two virtual community platforms in China. One of the research site, Douban (http://www.douban.com/), is a Chinese website allowing registered users to record information and create content related to films, books, music, and recent events and activities in Chinese cities. It was launched in 2005. Douban also owns an internet radio station. Douban has about 160 million registered users. Another research site, Sina Weibo (http://weibo.com), is a Chinese microblogging website. It is one of the most popular sites in China, in use by well over 30\% of Chinese Internet users, with a market penetration similar to what Twitter has established in the USA. It was launched by SINA Corporation in 2009, and has 503 million registered users. About 100 million messages are posted each day on Sina Weibo. The two research sites chosen represent two types of virtual communities categorized by [53]: interest-based community (Douban) and relational-based community (Sina Weibo). Through the inclusion of two communities, the study sought to extend the generalizability of the findings by exploring the differentiation of self-determination theory and virtual community identification across different settings.

\subsection{Measurement}

This study used the existing scales whenever possible and adapted them to the virtual community context (see scale resources in Table 1). The multidimensional constructs used 7-point Likert-type scales. Based on literature research, an initial set of items was generated. 
Table 1. Construct measures and sources.

\begin{tabular}{ccc}
\hline Constructs & Scale Sources & 7-Points Likert-Type Scale \\
\hline $\begin{array}{c}\text { Environmental characteristics of } \\
\text { virtual communities }\end{array}$ & Biocca et al. (2003) [54] & 1-strongly disagree or never like that \\
& Schroeder et al. (2001) [55] & 7-strongly agree or always like that \\
\hline \multirow{2}{*}{ Satisfied psychological needs } & Deci et al. (2001) [56] & 1-not accurate \\
& Ilardi et al. (1993) [57] & 7-very accurate \\
& Kasser et al. (1992) [58] & 1-not accurate \\
Virtual community identification & Brown et al. (1986) [47] & Crocke \& Luhtanen (1990) [59] \\
& Ellemers et al. (1999) [38] & 7-very accurate \\
& Rosenberg (1965) [60] & 1-strongly disagree \\
Sustained participation & Wasko \& Faraj (2005) [40] & 7-strongly agree \\
\hline
\end{tabular}

Next, to enhance the constructs' face validity, this study worked with Douban and Sina Weibo marketing managers to evaluate each item with respect to wording, fit with construct, completeness, and uniqueness. The study rephrased improperly worded items and deleted those that did not fit the construct definition. In the final step, the study invited 60 Douban and Sina Weibo users to participate in a pretest, obtaining 52 fully completed responses. These respondents provided open-ended feedback on the questionnaire. This study used this information to make several minor changes to wording and finalized the items used for the main study. English translations of the study measures are provided in the Appendix A.

\subsection{Data Collection}

In total, 585 complete responses from Douban were received. There were 506 valid responses, yielding a valid response rate of $86.5 \%$. Meanwhile a total of 237 complete responses from the Sina Weibo were received. There were 210 valid responses, yielding a valid response rate of $88.6 \%$. As this study is to investigate the respondents' sustained participation, the study screened out users who have been participating for more than one year in the community (considered as sustained participants) to conduct the following data analysis. After screening, Douban has 432 sustained participants, and Sina Weibo has 191 sustained participants. Table 2 presents an overview of the sample characteristics.

Table 2 shows that among the respondents from both Douban and Sina Weibo, the proportion of female users is relatively higher, and the majority is in the age group of 21-30 years. Furthermore, most of the members have a bachelor's degree or higher (80\% in Douban and $94 \%$ in Sina Weibo). In terms of the length of involvement in the community, among the respondents from Douban, $38 \%$ have been involved for $1-2$ years, $24 \%$ for $2-3$ years, and $38 \%$ for more than 3 years. Comparatively, among the respondents from Sina Weibo, $41 \%$ have been involved for $1-2$ years, $23 \%$ for $2-3$ years, and $36 \%$ for more than 3 years. It shows that there is no significant difference in the demographic profile of both communities' respondents.

Table 2. Sample characteristics.

\begin{tabular}{ccc}
\hline Overall Characteristics & $\begin{array}{c}\text { Douban } \\
\mathbf{( N = 4 3 2 )}\end{array}$ & $\begin{array}{c}\text { Sina Weibo } \\
\mathbf{( N = 1 9 1 )}\end{array}$ \\
\hline Gender & & \\
male & $160(37 \%)$ & $78(41 \%)$ \\
female & $272(63 \%)$ & $113(59 \%)$ \\
\hline
\end{tabular}


Table 2. Cont.

\begin{tabular}{ccc}
\hline Overall Characteristics & $\begin{array}{c}\text { Douban } \\
\mathbf{N}=\mathbf{4 3 2})\end{array}$ & $\begin{array}{c}\text { Sina Weibo } \\
\mathbf{( N = 1 9 1 )}\end{array}$ \\
\hline Age & $74(17 \%)$ & $28(15 \%)$ \\
20 years and younger & $331(76 \%)$ & $124(65 \%)$ \\
$21-30$ years & $24(6 \%)$ & $38(20 \%)$ \\
$31-40$ years & $3(1 \%)$ & $1(1 \%)$ \\
$41-50$ years & $0(0 \%)$ & $0(0 \%)$ \\
Over 50 years & & $4(2 \%)$ \\
Education & $29(7 \%)$ & $7(4 \%)$ \\
High school and lower & $56(13 \%)$ & $92(48 \%)$ \\
College & $273(63 \%)$ & $88(46 \%)$ \\
Undergraduate & $74(17 \%)$ & $72(38 \%)$ \\
Master and above & & $46(24 \%)$ \\
Annual Income (in thousand) & $199(46 \%)$ & $52(27 \%)$ \\
Less than 10 & $129(30 \%)$ & $21(11 \%)$ \\
$10-50$ & $101(23 \%)$ & $79(41 \%)$ \\
$50-300$ & $3(1 \%)$ & $44(23 \%)$ \\
Over 300 & & $68(36 \%)$ \\
\hline Length of the Participation in the Community & $166(38 \%)$ &
\end{tabular}

\section{Results and Analyses}

The theoretical model is multistage, suggesting the need for a structural equation modeling technique that simultaneously tests multiple relationships. This study uses SPSS and AMOS as the main statistical technique.

\subsection{Reliability and Validity}

The structural validity mainly is assessed by using the Kaiser-Meyer-Olkin (KMO) measure of the sampling adequacy test and Bartlett's test of sphericity. Before analyzing the validity, we must first carry out KMO and Bartlett's test of sphericity to confirm whether the data are suitable for factor analysis. The results of the tests show that all variables of the KMO scale are greater than 0.7 , the $\chi^{2}$ value of Bartlett's test of sphericity was significant, meaning that the common factors exist between the scale items and therefore they are suitable for carrying out a factor analysis. The results of the validity analysis of Douban and Sina Weibo are shown in Table 3. The loading coefficients of the factors are an important indicator for inspecting the validity of scales, as shown in Table 3, the loading coefficients are greater than 0.5 [61]; therefore, we consider the design of the scale to be effective.

Based on the survey data from the 432 responses of the Douban and the 191 responses of Sina Weibo, we use SPSS for analyzing the measurement reliability. As shown in Table 4, each Cronbach's $\alpha$ is greater than 0.7 , we believe that these measurements have a relatively high internal reliability. 
Table 3. Factor loading and accumulated variance.

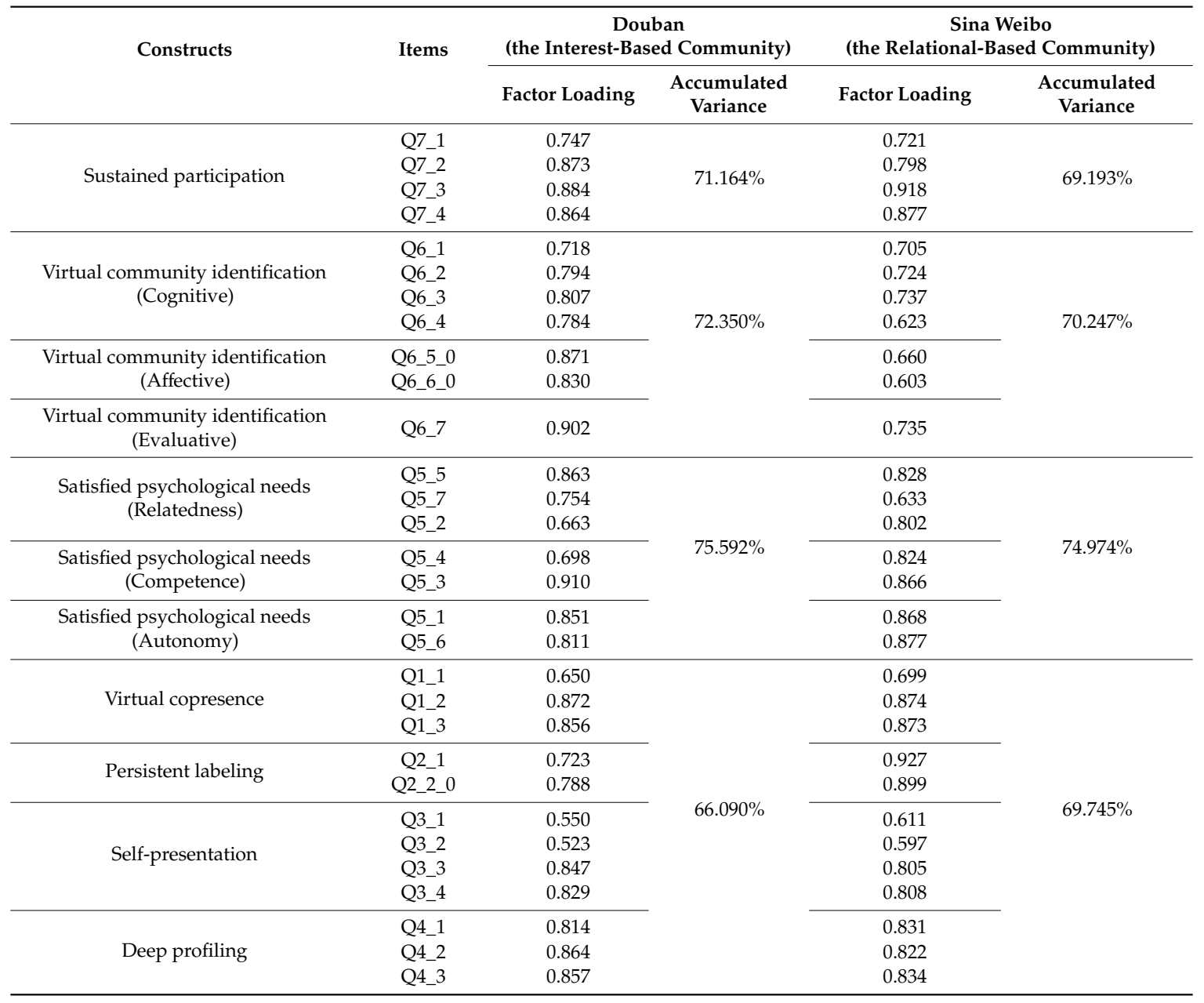

Table 4. Cronbach's Alpha.

\begin{tabular}{cccc}
\hline Constructs & \multirow{2}{*}{ N of Items } & Douban & Sina Weibo \\
\cline { 3 - 4 } & & Cronbach's $\boldsymbol{\alpha}$ & Cronbach's $\boldsymbol{\alpha}$ \\
\hline Sustained participation & 4 & 0.861 & 0.849 \\
Virtual community identification & 7 & 0.745 & 0.706 \\
Satisfied psychological needs & 7 & 0.826 & 0.717 \\
Environmental characteristics & 12 & 0.799 & 0.753 \\
Virtual copresence & 3 & 0.759 & 0.782 \\
Persistent labeling & 2 & 0.738 & 0.805 \\
Self-presentation & 4 & 0.721 & 0.715 \\
Deep profiling & 3 & 0.854 & 0.838 \\
\hline
\end{tabular}

\subsection{Common Method Variance}

Because our constructs are measured in a survey-based study, common method bias arises possibly [62,63]. To address the possibility, this study followed Podsakoff's et al. [63,64] method to include a common method factor in a structural equation model. The study used AMOS6.0 to test the effects of interest either with or without including a common method factor. The coefficients of independent variables did not change substantially.

\subsection{Hypothesis Tests-Douban (Interest-Based Community)}

To test the research hypotheses, this study used AMOS6.0 to evaluate the structural equation model. 
In Table 5, the fit statistics for the full model are as follows: $\chi 2(374)=728.324, p \approx 0.00, \chi 2 / \mathrm{df}<2$, RMSEA $<0.08$, GFI and AGFI $\approx 0.9, \mathrm{NFI} \approx 0.9$, and TLI and CFI $>0.9$. The $\chi 2$ is significant $(p<0.05)$; however, this is usually the case for large sample sizes like the one we have. All the other statistics are relatively good. Results indicate a good model fit.

Table 5. Fit statistics for the full model (the interest-based community-Douban).

\begin{tabular}{ccccccccc}
\hline \multicolumn{4}{c}{ Absolute Fit Index } & \multicolumn{4}{c}{ Relative Fit Index } \\
\hline$\chi^{2}$ & $\mathrm{df}$ & $\chi 2 / \mathrm{df}$ & RMSEA & GFI & AGFI & NFI & TLI & CFI \\
728.324 & 374 & 1.947 & 0.047 & 0.896 & 0.871 & 0.876 & 0.924 & 0.935 \\
\hline
\end{tabular}

Table 6 shows the internal consistency statistics for construct measures. As Table 6 shows, the reliability of the combination of all constructs is greater than 0.6 , and the average variance extracted is greater than 0.5 [65]. Therefore, good internal consistency is indicated.

Table 6. Internal consistency statistics (the interest-based community-Douban).

\begin{tabular}{ccc}
\hline Constructs & Construct Reliability (CR) & Average Variance Extracted(AVE) \\
\hline Virtual copresence & 0.7881 & 0.5669 \\
Persistent labeling & 0.6297 & 0.5213 \\
Self-presentation & 0.7458 & 0.5010 \\
Deep profiling & 0.8555 & 0.6647 \\
Satisfied psychological needs & 0.8371 & 0.6342 \\
Virtual community identification & 0.6198 & 0.5031 \\
Sustained participation & 0.8323 & 0.5556 \\
\hline
\end{tabular}

The results of path analysis are shown in Figure 2.

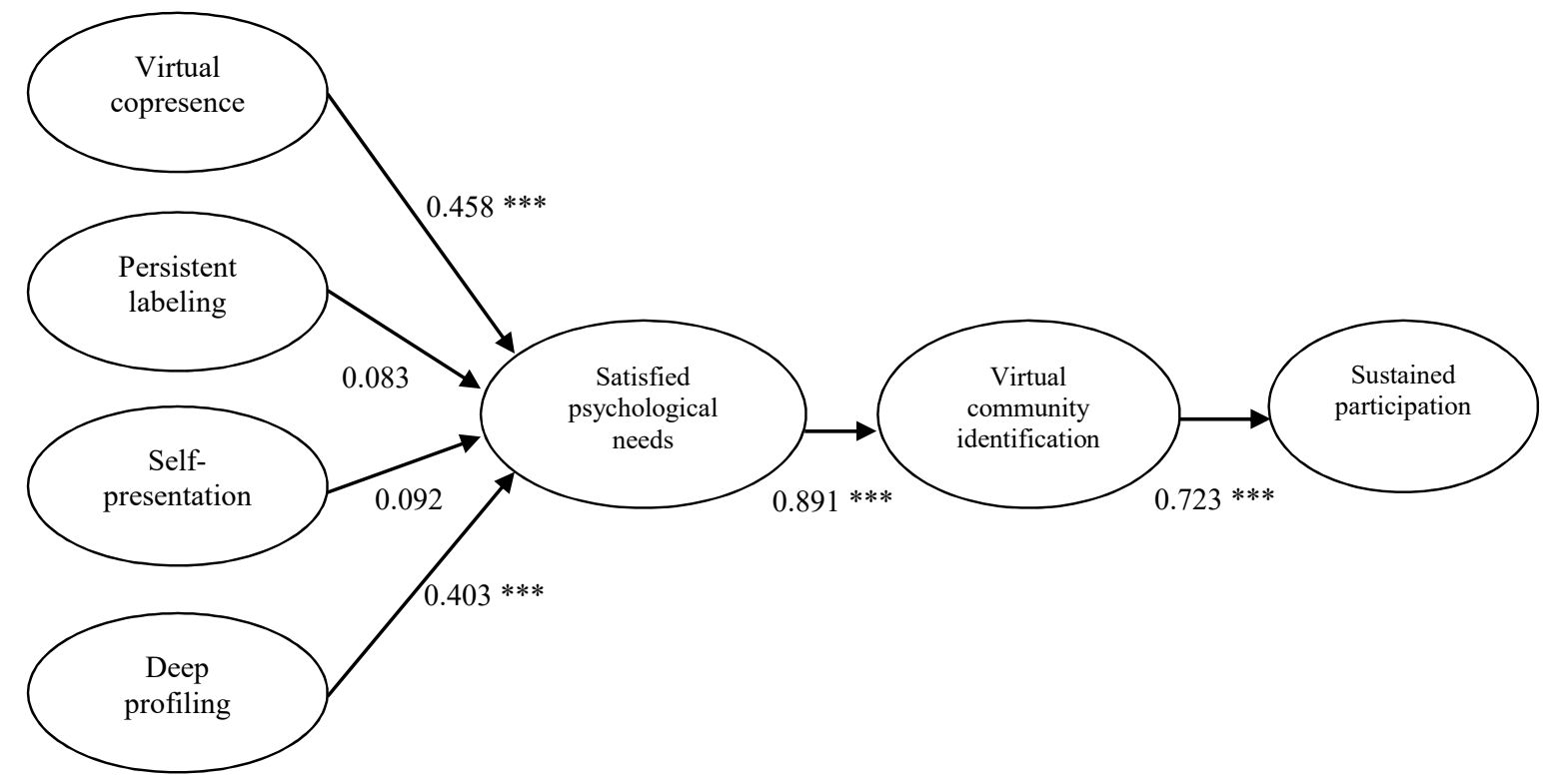

Figure 2. The path coefficients (the interest-based community-Douban); Note: ${ }^{*} p<0.05,{ }^{* *} p<0.01$, *** $p<0.001$.

\subsection{Hypothesis Tests-Sina Weibo(Relational-Based Community)}

In Table 7 , the fit statistics for full model in Sina Weibo are as follows: $\chi 2(377)=699.405, p \approx 0.00$, $\chi 2 / \mathrm{df}<2$, RMSEA $<0.08$, GFI and AGFI $\approx 0.9$, and NFI, TLI, and CFI $\approx 0.9$. The $\chi 2$ is significant $(p<$ 
0.05); however, all the other statistics are relatively good, which means that the overall fit of the model is acceptable.

Table 7. Fit statistics for the full model (the relational-based community—Sina Weibo).

\begin{tabular}{ccccccccc}
\hline \multicolumn{3}{c}{ Absolute Fit Index } & \multicolumn{4}{c}{ Relative Fit Index } \\
\hline$\chi^{2}$ & df & $\chi 2 /$ df & RMSEA & GFI & AGFI & NFI & TLI & CFI \\
699.405 & 377 & 1.855 & 0.067 & 0.887 & 0.862 & 0.858 & 0.879 & 0.899 \\
\hline
\end{tabular}

Table 8 shows the internal consistency statistics for construct measures in Sina Weibo. As Table 8 shows, the reliability of the combination of all constructs is greater than 0.6 , and the average variance extracted is greater than 0.5 . Therefore, good internal consistency is also indicated.

Table 8. Internal consistency statistics (the relational-based community—Sina Weibo).

\begin{tabular}{ccc}
\hline Constructs & Construct Reliability (CR) & Average Variance Extracted (AVE) \\
\hline Virtual copresence & 0.8051 & 0.5900 \\
Persistent labeling & 0.7887 & 0.6174 \\
Self-presentation & 0.7927 & 0.5051 \\
Deep profiling & 0.8494 & 0.6579 \\
Satisfied psychological needs & 0.7519 & 0.5038 \\
Virtual community identification & 0.6198 & 0.5031 \\
Sustained participation & 0.8895 & 0.6728 \\
\hline
\end{tabular}

The path coefficients in the structural model are shown in Figure 3.

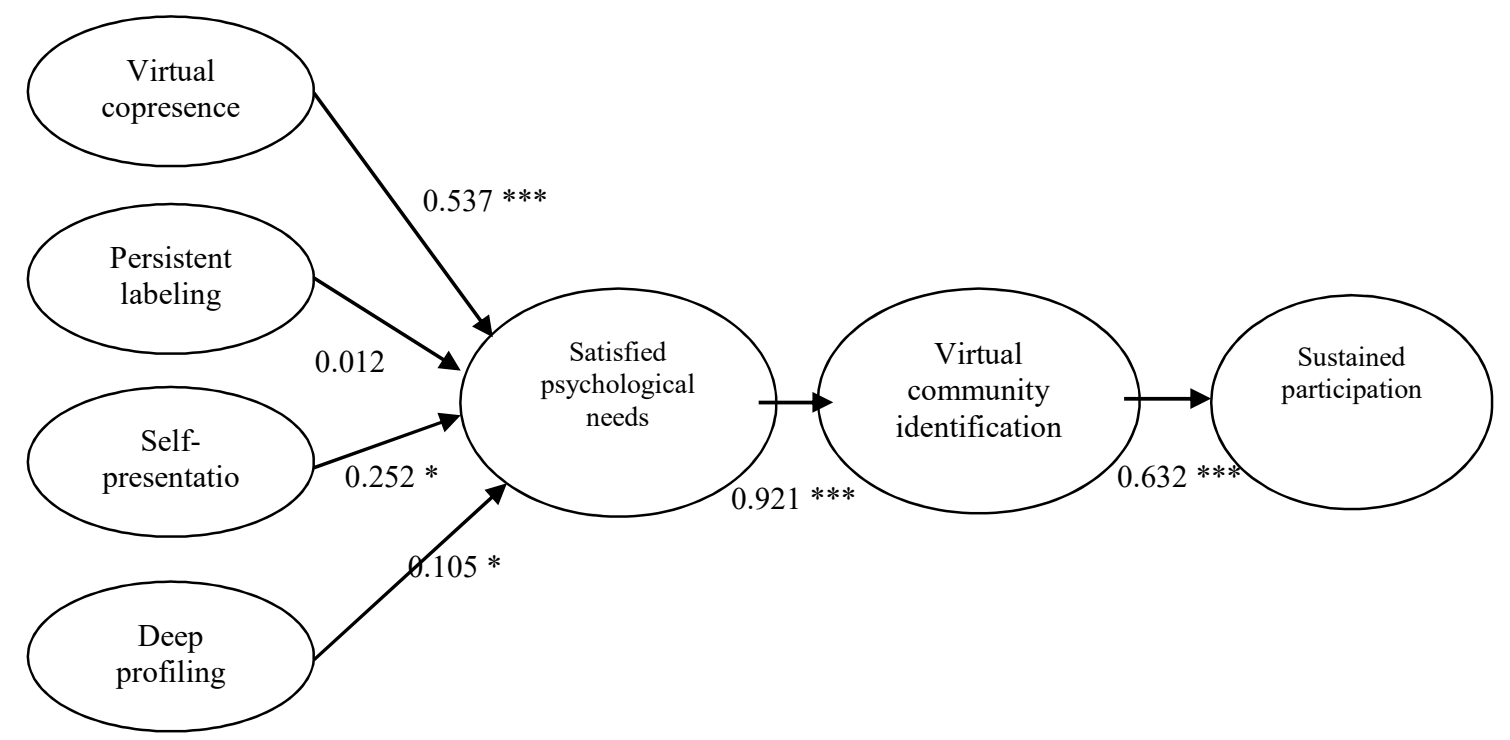

Figure 3. The path coefficients (the relational-based community-Sina Weibo). Note: ${ }^{*} p<0.05,{ }^{* *} p<$ $0.01,{ }^{* *} p<0.001$.

The results of hypothesis tests in Douban and Sina Weibo are summarized in Table 9. Data from Douban support Hypotheses 1a, 1d, 2, and 3. Data from Sina Weibo support Hypotheses 1a, 1c, 1d, 2 , and 3. Both communities support the posited links between virtual copresence (H1a) and deep profiling (H1d) and satisfied psychology needs. However, the relationship between persistent labeling and satisfied psychology needs (H1b) is not supported in either community. Moreover, the relationship between self-presentation and satisfied psychology needs (H1c) is significant for Douban but not for Sina Weibo. In both communities, satisfied psychology needs significantly and positively relate to virtual community identification (H2), which, in turn, relates to sustained participation (H3). 
Table 9. Results of the hypotheses testing.

\begin{tabular}{ccc}
\hline \multicolumn{1}{c}{ Research Hypotheses } & Path Description & Results \\
\hline $\begin{array}{c}\text { H1a. Community artifacts supporting for } \\
\text { virtual copresence is positively related to } \\
\text { satisfaction of psychological needs. }\end{array}$ & $\begin{array}{c}\text { Virtual copresence } \rightarrow \text { Satisfied } \\
\text { psychological needs }\end{array}$ & Supported \\
\hline $\begin{array}{c}\text { H1b. Community artifacts supporting for } \\
\text { persistent labeling is positively related to } \\
\text { satisfaction of psychological needs. }\end{array}$ & $\begin{array}{c}\text { Persistent labeling } \rightarrow \text { Satisfied } \\
\text { psychological needs }\end{array}$ & Not Supported \\
\hline $\begin{array}{c}\text { H1c. Community artifacts supporting for } \\
\text { self-presentation is positively related to } \\
\text { satisfaction of psychological needs. }\end{array}$ & $\begin{array}{c}\text { Self-presentation } \rightarrow \text { Satisfied } \\
\text { psychological needs }\end{array}$ & $\begin{array}{c}\text { Supported } \\
\text { (relational-based community) } \\
\text { Not supported }\end{array}$ \\
\hline $\begin{array}{c}\text { H1d. Community artifacts supporting for } \\
\text { deep profiling is positively related to } \\
\text { satisfaction of psychological needs. }\end{array}$ & $\begin{array}{c}\text { Deep profiling } \rightarrow \text { Satisfied } \\
\text { psychological needs }\end{array}$ \\
\hline $\begin{array}{c}\text { H2. Users' satisfied psychological needs } \\
\text { are positively related to their virtual } \\
\text { community identification. }\end{array}$ & $\begin{array}{c}\text { Satisfied psychological needs } \rightarrow \\
\text { Virtual community identification }\end{array}$ & Supported \\
\hline $\begin{array}{c}\text { H3. Virtual community identification is } \\
\text { positively related to sustained } \\
\text { participation behavior for users. }\end{array}$ & $\begin{array}{c}\text { Virtual community identification } \\
\rightarrow \text { Sustained participation }\end{array}$ & Supported \\
\hline
\end{tabular}

\section{Discussion}

From the perspective of the self-determination theory, this study explored the psychological mechanism of how satisfied psychological needs influenced the users' sustained participation through the process of identification in the virtual community environment. This study focused on two types of communities, an interest-based community (Douban) and a relational-based community (Sina Weibo), and carried out verification for the proposed hypothesis.

Regarding the relationship between community artifacts and the satisfied psychological needs, this study discovered that the community artifacts, which supported virtual copresence and deep profiling, could enhance the satisfaction of the users' psychological needs, which was verified in both the interest-based community (Douban) and the relational-based community (Sina Weibo). Through use of virtual copresence, the users can feel other users' presence in the same community, weakening the Internet's barrier of not seeing each other, creating an environment in which people can face each other as in reality and strengthening the users' trust in other users and the community. Through use of deep profiling, the users can autonomously access others' exposed information and their performance in the community, so that they can deepen their understanding of the others, which makes it easier to build relationships with other people. In this process, the users in virtual community gradually remove their precautions and start to participate in the community actively. Through taking part in the community's activities they can demonstrate their competence and obtain the satisfaction of their inner psychological needs. This shows that in the virtual environment, the community artifacts supporting virtual copresence and deep profiling can enhance the satisfaction of users' inner psychological needs.

The relationship between persistent labeling and satisfied psychological needs was not supported in both the interest-based community (Douban) and the relational-based community (Sina Weibo). This study posits that in Douban, the main reason for users to build relationships is due to the users' common interests, while the true identity of the other person is not found out; at the same time, the user name also only serves the purpose of identification in the beginning. Once the relationship is established between the users, they interact more frequently and become more familiar with each other; hence, the role of the username for identification was not salient anymore. Therefore, it is understandable that the effect of persistent labeling on the satisfaction of the sustained participants' psychological needs was not significant. With regard to the relational-based community (Sina Weibo), most of the users have "offline" contact as well, and are familiar with the other person's identity; 
at the same time, the username's role of identification is somewhat weakened, and thus, it is also understandable that the effect of persistent labeling on the satisfaction of users' psychological needs in the relational-based community is nonsignificant.

This study finds a remarkable difference in the path from self-presentation to satisfied psychological needs, which is not significant in the interest-based community (Douban) and significant in the relational-based community (Sina Weibo). Thus this effect is relevant to the type of the virtual community. Douban belongs to the common interest communities, the approval of the interests and information determines the extent of the satisfaction of the users' psychological needs, while the effect of the personal information shown is rather small. On the other hand, Sina Weibo belongs to the relational-support communities, the establishment of relationships requires the presentation of personal information, which also enhances the identifiability and quality of the relationship; therefore, self-presentation has a significant effect on satisfied psychological needs.

The relationship between satisfied psychological needs and virtual community identification received empirical support in both communities. Regarding the three types of psychological needs of the self-determination theory, previous researchers found out that through satisfying an individual's autonomous, relational and competence psychological needs, the virtual environment factors and the individuals' interaction enhances intrinsic motivation and internalization of extrinsic motivation, eventually motivating the working behavior of the individual and enhancing the mental health of the individual.

Within the virtual environment, the relationship between virtual community identification and sustained participation is supported by both the interest-based community (Douban) and the relational-based community (Sina Weibo), which means that the users' virtual community identification can contribute to their sustained participation in the virtual community.

\section{Conclusions}

Our research results show that the community artifacts supporting the use of virtual copresence, self-presentation, and deep profiling can enhance the satisfaction of its users' inner psychological needs. For this reason, creating a convenient environment for users' sustained participation is of crucial significance for the virtual community's sustained development. From a business perspective, the manager should take advantage of all community artifacts to create a convenient and trusted environment for the virtual community users, encouraging the virtual community users to actively participate in the community activities.

Our study found out that the satisfied psychological needs (autonomy, competence, relatedness) can contribute to the virtual community identification. The importance of the satisfaction of the users' inner psychological needs for the virtual community is confirmed. Therefore with regard to the manager, knowing the users' different requirements and motivations is very important. At the same time, while supporting and launching activities in the virtual community, the community users' inner psychological requirements should be fully taken into account.

Furthermore, our study confirmed that in the virtual environment, the users' identification can contribute to sustained participation. Therefore, for users who have formed identification with the virtual community, the virtual community manager can strengthen their sense of belonging and superiority by intensifying the difference between the members inside and outside the community; thus, further increasing their sense of belonging towards the community, and promoting their sustained participation; for users who have not yet established identification with the virtual community, the virtual community manager can form the virtual community's specialty and superiority by emphasizing the difference to other communities, also attracting their attention by creating or strengthening the common ground of the community and the users, strengthening the cognitive resonance, and then impelling them to form identification with the community, further enhancing sustained participation, thus contributing to the virtual community's sustainability. 


\section{Limitations and Directions Further Research}

This study found out the sustained participation of virtual community members using the self-report method scale measurement. If the users' actual behavior data could be obtained further, the research results could be further validated and enriched.

With the rapid development of information technology, the elements of the virtual environment are becoming increasingly more diverse, not just being limited to chatting, inbound mails, username, labeling, avatar, and self-presentation elements. Now, it has already extended to offline activities, same city activities, small-group activities, etc. Porter, Donthu, Macelroy, and Wydra [30] also show that intensifying the interconnection between the community members promotes the community members' sustained participation, encouraging the members to form small groups based on the location, common interests, or other characteristics, and also encouraging the users to meet face to face, increasing the opportunities of offline contact, increasing the relationships and emotional ties between the community members, and thus promoting the community members' active sustained participation. Therefore, future studies can consider digging further into virtual community elements exploring how the users' active sustained participation can be promoted more effectively in the virtual community.

In addition, our research findings are limited to just only our dataset in China. Therefore, testing based on a different dataset in different countries will be encouraged.

Funding: This research was funded by the National Natural Science Foundation of China, grant number 71672038 and 71972043 and the China Scholarship Council, grant number 201706105007.

Acknowledgments: The authors sincerely thank seminar participants at the Center for Data-Driven Managerial Decision Making.

Conflicts of Interest: The authors declare no conflicts of interest.

\section{Appendix A Summary of Constructs and Their Measures}

\section{Virtual copresence}

Q1_1 I find that people respond to my posts or private messages quickly.

Q1_2 To what extent, if at all, did you ever have a sense of "being there with other people" in this community?

Q1_3 To what extent, if at all, did you have a sense that you were together with other members in the virtual environment of this community?

\section{Persistent labeling}

Q2_1 I consistently use a single ID to communicate with other members in this community.

Q2_2 I use more than one ID in this community (reversed). (Q2_2_0 = 8- Q2_2)

\section{Self-presentation}

Q3_1 I share my photos or other personal information with people from this community.

Q3_2 I present information about myself in my profile.

Q3_3 I use a special (or meaningful) signature in this community that differentiates me from others.

Q3_4 I use a special (meaningful) name or nickname in this community that differentiates me from others.

\section{Deep profiling}

Q4_1 I think that other people search the archive to find out more about me.

Q4_2 I think that other people have read my previous posts.

Q4_3 I think that other people look at my profile to find out more about me.

\section{Satisfied psychological needs}

Q5_1 I am free to express my ideas and opinions in this community.

Q5_2 I consider the people I am with in this community to be my friends.

Q5_3 I have been able to learn interesting new skills in this community.

Q5_4 Most days, I feel a sense of accomplishment from being in this community. 
Q5_5 People in this community care about me.

Q5_6 I feel like I can pretty much be myself in this community.

Q5_7 People in this community are pretty friendly towards me.

\section{Virtual community identification}

Q6_1 I identify with other members of the community.

Q6_2 I am like other members of the community.

Q6_3 I can reflect very well who I am.

Q6_4 When I talk about this community I often want to say "We" instead of "They".

Q6_5 I dislike being a member of the community (reversed). (Q6_5_0 = 8-Q6_5)

Q6_6 I would rather belong to the other communities (reversed). (Q6_6_0 = 8-Q6_6)

Q6_7 I feel good about this community.

\section{Sustained participation}

Q9_1 I often help other people in this community who need help/information from other members.

Q9_2 I take an active part in this community.

Q9_3 I have contributed knowledge to this community.

Q9_4 I have contributed by imparting knowledge to other members that resulted in the development of new insights for them.

\section{References}

1. Bateman, P.J.; Gray, P.; Butler, B.S. The impact of community commitment on participation in online communities. Inf. Syst. Res. 2011, 22, 841-854. [CrossRef]

2. De Valck, K.; Van Bruggen, G.H.; Wierenga, B. Virtual communities: A marketing perspective. Decis. Support Syst. 2009, 47, 185-203. [CrossRef]

3. Dholakia, U.M.; Bagozzi, B.P.; Pearo, L.K. A social influence model of consumer participation in networkand small-group-based virtual communities. Int. J. Res. Mark. 2004, 21, 241-263. [CrossRef]

4. Koh, J.; Kim, U.G.; Butler, B.; Bock, G.W. Encouraging participation in virtual communities. Commun. ACM 2007, 50, 69-73. [CrossRef]

5. Leal, G.P.A.; Hor-Meyll, L.F.; de Paula Pessôa, L.A.G. Influence of virtual communities in purchasing decisions-The participants' perspective. J. Bus. Res. 2014, 67, 882-890. [CrossRef]

6. Lin, H.-F. Determinants of successful virtual communities: Contribution from system characteristics and social factors. Inf. Manag. 2008, 5, 522-527. [CrossRef]

7. Wang, Y.; Ma, S.S.; Li, D. Customer participation in virtual brand communities: The self-construal perspective. Inf. Manag. 2015, 52, 577-587. [CrossRef]

8. Bagozzi, R.P.; Dholakia, U.M. Intentional social action in virtual communities. J. Interact. Mark. 2002, 16, 2-21. [CrossRef]

9. Dholakia, U.M.; Blazevic, V.; Wiertz, C.; Algesheimer, R. Communal service delivery: How customers benefit from participation in firm-hosted virtual P3 communities. J. Serv. Res. 2009, 12, 208-226. [CrossRef]

10. Fang, C.; Zhang, J. Users' continued participation behavior in social Q\&A communities: A motivation perspective. Comput. Hum. Behav. 2019, 92, 87-109.

11. Liang, R.-Y.; Guo, W.; Zhang, L.-H.; Wang, L. Investigating sustained participation in open design community in China: The antecedents of user loyalty. Sustainability 2019, 11, 2420. [CrossRef]

12. Arazy, O.; Gellatly, I.; Brainin, E.; Nov, O. Motivation to share knowledge using wiki technology and moderating effect of role perceptions. J. Am. Soc. Inf. Sci. Technol. 2016, 67, 2362-2378. [CrossRef]

13. Roberts, J.A.; Hann, I.; Slaughter, S.A. Understanding the motivations, participation, and performance of open source software developers: A longitudinal study of the apache projects. Manag. Sci. 2006, 52, 984-999. [CrossRef]

14. Toubia, O.; Stephen, A. Intrinsic vs. image-related utility in social media: Why do people contribute content to twitter? Mark. Sci. 2013, 32, 368-392. [CrossRef]

15. Lin, K.Y.; Lu, H.P. Why people use social networking sites: An empirical study integrating network externalities and motivation theory. Comput. Hum. Behav. 2011, 27, 1152-1161. [CrossRef] 
16. Ryan, R.M.; Deci, E.L. Self-determination theory and the facilitation of intrinsic motivation, social development, and well-being. Am. Psychol. 2000, 55, 68-78. [CrossRef]

17. Ma, M.; Agarwal, R. Through a glass darkly: Information technology design, identity verification, and knowledge contribution in online communities. Inf. Syst. Res. 2007, 18, 42-67. [CrossRef]

18. Rezvani, A.; Khosravi, P.; Dong, L. Motivating users toward continued usage of information systems: Self-determination theory perspective. Comput. Hum. Behav. 2017, 76, 263-275. [CrossRef]

19. Zhang, Y. Understanding the sustained use of online health communities from a self-determination perspective. J. Am. Soc. Inf. Sci. Technol. 2016, 67, 2842-2857. [CrossRef]

20. Rishika, R.; Kumar, A.; Janakiraman, R.; Bezawada, R. The effect of customers' social media participation on customer visit frequency and profitability: An empirical investigation. Inf. Syst. Res. 2013, 24, 108-127. [CrossRef]

21. Zhang, C.; Hahn, J.; De, P. Continued participation in online innovation communities: Does community response matter equally for everyone? Inf. Syst. Res. 2013, 24, 1112-1130. [CrossRef]

22. Dholakia, R.R.; Chiang, K.P. Shoppers in cyberspace: Are they from venus or mars and does it matter? J. Consum. Psychol. 2003, 13, 171-176. [CrossRef]

23. Foster, A. A nonlinear model of information-seeking behavior. J. Am. Soc. Inf. Sci. Technol. 2004, 55, $228-237$. [CrossRef]

24. Sun, Y.; Fang, Y.; Lim, K.H. Understanding sustained participation in transactional virtual communities. Decis. Support Syst. 2012, 53, 12-22. [CrossRef]

25. Peddibhotla, N.B.; Subramani, M.R. Contributing to public document repositories: A critical mass theory perspective. Organ. Stud. 2007, 28, 327-346. [CrossRef]

26. Shah, S.K. Motivation, governance, and the viability of hybrid forms in open source software development. Manag. Sci. 2006, 52, 1000-1014. [CrossRef]

27. Minton, E.A.; Spielmann, N.; Kahle, L.R.; Kim, C.-H. The subjective norms of sustainable consumption: A cross-cultural exploration. J. Bus. Res. 2018, 82, 400-408. [CrossRef]

28. Barab, S.A.; Duffy, T.M. From practice fields to communities of practice. In Theoretical Foundations of Learning; Jonassen, D.H., Land, S.M., Eds.; Lawrence Erlbaum: Mahwah, NJ, USA, 2000; pp. 25-55.

29. Hsu, M.-H.; Ju, Y.L.; Yen, C.-H.; Chang, C.-M. Knowledge sharing behavior in virtual communities: The relationship between trust, self-efficacy, and outcome expectations. Int. J. Hum. -Comput. Stud. 2007, 65, 153-169. [CrossRef]

30. Porter, C.E.; Donthu, N.; Macelroy, W.H.; Wydra, D. How to foster and sustain engagement in virtual communities. Calif. Manag. Rev. 2011, 53, 80-110. [CrossRef]

31. Aryee, S.; Walumbwa, F.O.; Mondejar, R.; Chu, C.W.L. Accounting for the influence of overall justice on job performance: Integrating self-determination and social exchange theories. J. Manag. Stud. 2015, 52, 231-252. [CrossRef]

32. Deci, E.L.; Ryan, R.M. The "what" and "why" of goal pursuits: Human needs and the self-determination of behavior. Psychol. Inq. 2000, 11, 227-268. [CrossRef]

33. Deci, E.L.; Ryan, R.M. The Handbook of Self-Determination Research, 1st ed.; University of Rochester Press: New York, NY, USA, 2013.

34. Gagné, M.; Deci, E.L. Self-determination theory and work motivation. J. Organ. Behav. 2005, 26, 331-362. [CrossRef]

35. Elstak, M.N.; Bhatt, M.; Van Riel, C.B.M.; Pratt, M.G.; Berens, G.A.J.M. Organizational identification during a merger: the role of self-enhancement and uncertainty reduction motives during a major organizational change. J. Manag. Stud. 2015, 52, 32-62. [CrossRef]

36. Spears, R.; Lea, M. Panacea or panopticon? The hidden power in computer-mediated communication. Commun. Res. 1994, 21, 427-459. [CrossRef]

37. Tajfel, H. Social categorization, social identity and social comparison. In Differentiation between Social Groups: Studies in the Social Psychology of Intergroup Relations; Tajfel, H., Ed.; Academic Press: London, UK, 1978.

38. Ellemers, N.; Kortekaas, P.; Ouwerkerk, J.W. Self-categorization, commitment to the group, and group self-esteem as related but distinct aspects of social identity. Eur. J. Soc. Psychol. 1999, 29, 371-389. [CrossRef]

39. Hogg, M.A. The Social Psychology of Group Cohesiveness: From Attraction to Social Identity; New York University Press: New York, NY, USA, 1992. 
40. Wasko, M.M.; Faraj, S. Why should I share? Examining social capital and knowledge contribution in electronic networks of practice. Manag. Inf. Syst. Q. 2005, 29, 35-57. [CrossRef]

41. Przybylski, A.K.; Weinstein, N.; Murayama, K.; Lynch, M.F.; Ryan, R.M. The ideal self at play: The appeal of video games that let you be all you can be. Psychol. Sci. 2012, 23, 69-76. [CrossRef]

42. Partala, T. Psychological needs and virtual worlds: Case Second Life. Int. J. Hum. -Comput. Stud. 2011, 69, 787-800. [CrossRef]

43. Ryan, R.M.; Deci, E.L. On assimilating identities to the self: A self-determination theory perspective on internalization and integrity within cultures. In Handbook of Self and Identity; Leary, M.R., Tangney, J.P., Eds.; Guilford Press: New York, NY, USA, 2003.

44. Marcia, J.E. Development and validation of ego-identity status. J. Personal. Soc. Psychol. 1966, 3, 551-558. [CrossRef]

45. Luyckx, K.; Schwartz, S.J.; Soenens, B.; Vansteenkis, T.E.M.; Goossens, L. The path from identity commitments to adjustment: Motivational underpinnings and mediating mechanisms. J. Couns. Dev. 2010, 88, 52-60. [CrossRef]

46. Côté, J.E.; Levine, C. A critical examination of the ego identity status paradigm. Dev. Rev. 1988, 8, 147-184.

47. Brown, R.; Condor, S.; Mathews, A.; Wade, G.; Williams, J. Explaining intergroup differentiation in an industrial organization. J. Occup. Psychol. 1986, 59, 273-286. [CrossRef]

48. Mcalexander, J.H.; Schouten, J.W.; Koenig, H.F. Building brand community. J. Mark. 2002, 66, 38-54. [CrossRef]

49. Bergami, M.; Bagozzi, R.P. Self-categorization, affective commitment and group self-esteem as distinct aspects of social identity in the organization. Br. J. Soc. Psychol. 2000, 39, 555-557. [CrossRef] [PubMed]

50. Fang, Y.; Neufeld, D. Understanding sustained participation in open source software projects. J. Manag. Inf. Syst. 2009, 25, 9-50. [CrossRef]

51. Lave, J.; Wenger, E. Situated Learning: Legitimate Peripheral Participation; Cambridge University Press: New York, NY, USA, 1991.

52. Tsai, H.-T.; Pai, P. Explaining members' proactive participation in virtual communities. Int. J. Hum. -Comput. Stud. 2013, 71, 475-491. [CrossRef]

53. Armstrong, A.; Hagel III, J. The Real Value of Online Communities. Harv. Bus. Rev. 1996, 74, $134-141$.

54. Biocca, F.; Harms, C.; Burgoon, J.K. Toward a more robust theory and measure of social presence: Review and suggested criteria. Presence: Teleoperators Virtual 2003, 12, 456-482. [CrossRef]

55. Schroeder, R.; Steed, A.; Axelsson, A.S.; Heldal, I.; Abelin, Å.; Wideström, J.; Nilsson, A.; Slater, M. Collaborating in networked immersive spaces: As good as being there together? Comput. Graph. 2001, 25, 781-788. [CrossRef]

56. Deci, E.L.; Ryan, R.M.; Gagné, M.; Leone, D.R.; Usunov, J.; Kornazheva, B.P. Need satisfaction, motivation, and well-being in the work organizations of a former eastern bloc country. Personal. Soc. Psychol. Bull. 2001, 27, 930-942. [CrossRef]

57. Ilardi, B.C.; Leone, D.; Kasser, T.; Ryan, R.M. Employee and supervisor ratings of motivation: Main effects and discrepancies associated with job satisfaction and adjustment in a factory setting. J. Appl. Soc. Psychol. 1993, 23, 1789-1805. [CrossRef]

58. Kasser, T.; Davey, J.; Ryan, R.M. Motivation and employee-supervisor discrepancies in psychiatric vocational rehabilitation setting. Rehabil. Psychol. 1992, 37, 175-188. [CrossRef]

59. Crocker, J.; Luhtanen, R. Collective self-esteem and ingroup bias. J. Personal. Soc. Psychol. 1990, 58, 60-67. [CrossRef]

60. Rosenberg, M. Society and the Adolescent Self-image; Princeton University Press: Princeton, NJ, USA, 1965.

61. Falk, R.F.; Miller, N.B. A Primer for Soft Modeling; University of Akron Press: Akron, OH, USA, 1992.

62. Campbell, D.T.; Fiske, D.W. Convergent and discriminant validation by the multitrait-multimethod matrix. Psychol. Bull. 1959, 56, 81-105. [CrossRef]

63. Podsakoff, P.M.; Mackenzie, S.B.; Lee, J.Y.; Podsakoff, N.P. Common method biases in behavioral research: A critical review of the literature and recommended remedies. J. Appl. Psychol. 2003, 88, 879-903. [CrossRef] 
64. Podsakoff, P.M.; Mackenzie, S.B.; Podsakoff, N.P. Sources of method bias in social science research and recommendations on how to control it. Annu. Rev. Psychol. 2012, 63, 539-569. [CrossRef]

65. Fornell, C.; Bookstein, F.L. Two structural equation models: LISREL and PLS applied to consumer exit-voice theory. J. Mark. Res. 1982, 19, 440-452. [CrossRef]

(C) 2019 by the author. Licensee MDPI, Basel, Switzerland. This article is an open access article distributed under the terms and conditions of the Creative Commons Attribution (CC BY) license (http://creativecommons.org/licenses/by/4.0/). 